\title{
RELATIONSHIP BETWEEN THYROID FUNCTION AND INTENSIVE CARE UNIT MORTALITY IN CRITICALLY ILL PATIENTS AT ZAGAZIG UNIVERSITY HOSPITAL
}

\author{
Abd Elmonem F. Zaid, Mohamed H. Assy, Hatem M. Salem, Mohamed S.S. Saad, Mohamed R. Herzalla \\ Internal Medicine Departement,Faculty of Medicine, Zagazig University, Egypt
}

\begin{abstract}
Introduction: Thyroid hormones play a key role in the maintenance of body growthby modulating metabolism and the immune system. In the 20th century,researchers found that thyroid dysfunction is associated with theincreased mortality of patients admitted to the intensive care units (ICU). This study was conducted to evaluate the prognostic value of the thyroid functions; free triiodothyronine(FT3), total triiodothyronine (TT3), free thyroxin (FT4), total thyroxine (TT4) and thyroid-stimulating hormone (TSH) in unselected ICU patients.

Methods: A total of 183 unselected critically ill patients without known thyroid diseases were screened for eligibility and followed up during their ICU stay. Patient's baseline characteristics, the Acute Physiology and Chronic Health Evaluation II (APACHE II), thyroid hormones and C-reactive protein (CRP) levels were determined. The primary outcome was ICU mortality. The patients were divided into two groups; group (1) survivors and group (2) nonsurvivors. Potential predictors were analysed for possible association with outcomes. We also evaluated the ability of thyroid hormones together with APACHE II score to predict ICU.

Results:Among thyroid hormone functions, FT3had the greatest power to predict ICU mortality, as suggested by the largest area under the curve (AUC) of 0.838. The AUC for FT3 was nearly the same for APACHE II score (0.822) but greater than that for CRP (0.722). Multiple regression analysis revealed that FT3 and TSH levels, APACHE II score and CRP level could independently predict primary outcome. The addition of FT3 and TSH levels to APACHE II score gave an NRI of $55.80 \%$. The level of FT3 showed a significant negative correlation with APACHE II score $(r=-0.382$, $\mathrm{p}=0.000)$ and with CRP $(\mathrm{r}=-0.244, \mathrm{p}=0.001)$. The level of TSH showed a significant negative correlation with APACHE II score $(\mathrm{r}=-0.194, \mathrm{p}=0.008)$.

Conclusion: Among thyroid functions, the serum levels of both FT3 and TSH are the most powerful and independent predictors of ICU mortality. Moreover, the addition of FT3 and TSH to APACHE II score could significantly improve the ability to predict ICU outcome.
\end{abstract}

Key words:Thyroid Function, ICU, APACHE, Mortality

\section{INTRODUCTION}

D uring critical illness, changes in circulating hormone levels are acommon phenomenon .These alterations are correlated with the severityof morbidity and the outcomes of patients in ICU. Thyroid hormones play a key role in the maintenance of body growthby modulating metabolism and the immune system. In the 20th century,researchers found that thyroid dysfunction is associated with theincreased mortality of patients admitted to the ICU ${ }^{(\mathbf{1})}$.

These alterations in thyroid hormone levels are referred to as"euthyroid sick syndrome" (ESS) $\left(^{2)}\right.$ or"nonthyroidal illness syndrome" (NTIS) (3), which ischaracterized by low serum levels of FT3 and TT3and high levels of reverse T3 (rT3) accompanied by normal or low levelsof $\mathrm{T} 4$ and TSH.Many studies have confirmed the association between NTIS andadverse outcomes in patients with sepsis ${ }^{(4)}$,multiple trauma ${ }^{(5)}$, acute respiratory distress syndrome ${ }^{(6)}$, respiratory failure ${ }^{(7)}$, mechanicalventilation ${ }^{(\boldsymbol{8})}$ and even in unselected ICU patients ${ }^{(\mathbf{9})}$.

Although there are several validated prognostic models that use a variety of clinical and biochemical parameters, all models still far fromthe desired levels of accuracy ${ }^{(\mathbf{1 0})}$. The score on the APACHE II is the most widely used method to predict outcomes in ICUpatients, with an accuracy that is reported to be $77 \%{ }^{(10)}$. However, this score does not consider hormonal responses toillness, particularly serum levels of cortisol and thyroid hormones, whichhave been shown to be highly associated with mortality in critically illpatients ${ }^{(11)}$.

\section{SUBJECTS AND METHODS}

This prospective study has been carried out on patients admitted to the ICU of Internal Medicine Department,Faculty of Medicine, Zagazig University, during the period from November 2012 to April 2014.

* Subjects:

A total number of 183 patients were included and were classified into two main groups:

\section{Group I:}

Included 135 survived patients (75 males and 60 females), with age ranged from 18 to 85 years with a mean value and SD of $57.16 \pm 15.36$ years.This group was divided into 6 subgroups according to the diagnosis; 50neurological, 36 gastrointestinal, 13 renal, 21 cardiac, 10 pulmonary and 5poisoning patients.

\section{2) Group II:}

Included 48 non-survived patients (28 males and 20 females), with age rangedfrom 37 to 81 years with a mean value and SD of $60.71 \pm 10.58$ years.This group was divided into 6 subgroups according to the diagnosis; 10neurological, 20 
gastrointestinal, 2 renal, 8 cardiac, 6 pulmonary and 2 sepsis patients.

\section{*Inclusion criteria:}

Unselected critically ill patients admitted to medical ICU with their age more than 18 years.

*Exclusion criteria:

1. Age less than 18 years old.

2. Patients who refused to enter the study.

3. History of any thyroid disease.

4. Patients with a history of pregnancy within the previous 6 months.

5. Patients under any hormonal therapy except insulin use or taking oralamiodarone.

6. Patients with palpable thyroid nodule.

7. Patients who died or were discharged from ICU within 4 hours afteradmission.

8. Patients with a history of ICU admission within the previous 6 months.

* Methods:

All subjects of the study were subjected to the following:

A) Thorough history and full clinical examination

B) Routine investigations:

They were all done according to the methods applied in the laboratories of Zagazig university hospitals and included:

1- Complete blood picture (by automated blood counter).

2- Liver function tests: serum albumin, measured by kinetic method

3- Renal function tests: serum creatinine.

4- Arterial blood gases.

5- Serum electrolytes: sodium and potassium.

C- Special Investigation :

Specimen collection and preparation

Measurement of TT3, TT4, FT3, FT4 and TSH using Enzyme Linked Immuno-Sorbent Assay (ELISA).Five milliliters of peripheral blood were withdrawn from each patient in plain tube.Samples were collected by venipuncture, and the samples were centrifuged.The serum was removed and stored at $2-8^{\circ} \mathrm{C}$ until testing could be performed. If not tested within 8 hours of collection, the sampleswere storedat $-70^{\circ} \mathrm{C}$ and tested within 1 month.

\section{*Follow up:}

The patients' outcomes were observed after their ICU stay days formortality.

\section{*STATISTICAL ANALYSIS}

Data were coded and entered using the statistical package SPSS version21. Data were summarized using mean, standard deviation, median, minimum and maximum for quantitative variables and frequencies (number of cases) and relative frequencies (percentages) for categorical variables. Comparison of quantitative variables was done using unpaired Student's t-test or the Mann Whitney U test. For comparing categorical data, Chi square $(\chi 2)$ test wasperformed. Exact test was used instead when the expected frequency is lessthan 5 .

Correlations between variables were done using Pearson correlation coefficient. Receiver operating characteristic (ROC) curves were used to examine the performance of variables in predicting ICU mortality. The AUC was calculated from the ROC curve.

Univariate logistic regression analyses were performed to examine the association between mortality and each of the predictors separately. Odds ratio (OR) with $95 \%$ confidence intervals was calculated. We also conducted forward stepwise multivariate logistic regression analysis to determine the independent predictors of ICU mortality. Criteria of $\mathrm{P}<0.05$ for entry and $\mathrm{P} \geq$ 0.10 for removal were imposed in this procedure. Cox \& Snell R2 and Nagelkerke R2 correlation coefficients were calculated to assess the goodness of fit of the models. $\mathrm{P}$ value $<0.05$ was taken as statistically significant 


\section{RESULTS}

Table (1): Demographic data of the studied groups:

\begin{tabular}{|c|c|c|c|c|c|}
\hline & & \multicolumn{2}{|c|}{ Mortality } & & \multirow[b]{2}{*}{$P$ value } \\
\hline & & $\begin{array}{l}\text { Survivor } \\
(\mathbf{n}=135)\end{array}$ & $\begin{array}{c}\text { non-survivor } \\
(n=48)\end{array}$ & & \\
\hline \multirow{5}{*}{ Age } & Mean & 57.16 & 60.71 & \multirow{5}{*}{$\begin{array}{c}T= \\
-1.481\end{array}$} & \multirow{5}{*}{0.140} \\
\hline & Standard Deviation & 15.36 & 10.58 & & \\
\hline & Median & 57.00 & 60.00 & & \\
\hline & Minimum & 18.00 & 37.00 & & \\
\hline & Maximum & 85.00 & 81.00 & & \\
\hline \multirow{2}{*}{ Gender } & Female Number (\%) & $60(44.4 \%)$ & $20(41.7 \%)$ & \multirow{2}{*}{$X^{2}=0.111$} & \multirow{2}{*}{0.739} \\
\hline & Male Number (\%) & $75(55.6 \%)$ & $28(58.3 \%)$ & & \\
\hline
\end{tabular}

Table (1) describes demographic data of the studied groups and shows that there were non statistical significant differences between died and survived groups as regard age or gender $(\mathrm{P}=0.14)$.

Table (2): Association between diagnosis and mortality:

\begin{tabular}{|c|c|c|c|c|c|c|c|c|c|}
\hline & & \multicolumn{2}{|c|}{$\begin{array}{c}\text { Group I } \\
\text { (survivor) } \\
(\mathbf{n}=\mathbf{1 3 5})\end{array}$} & \multicolumn{2}{|c|}{$\begin{array}{c}\text { Group II } \\
\text { (non-survivor) } \\
(n=48)\end{array}$} & \multirow[t]{2}{*}{$\mathbf{X}^{2}$} & \multirow[t]{2}{*}{$P$ value } & \multirow[t]{2}{*}{$\mathbf{X}^{2}$} & \multirow[t]{2}{*}{$P$ value } \\
\hline & & Count & $\%$ & Count & $\%$ & & & & \\
\hline \multirow{7}{*}{ DIAGNOSIS } & $\begin{array}{c}\text { Neurologi } \\
\text { c }\end{array}$ & 50 & $37.0 \%$ & 10 & $20.8 \%$ & 26.3 & $<0.001$ & \multirow{7}{*}{15.2} & \multirow{7}{*}{0.024} \\
\hline & GIT & 36 & $26.7 \%$ & 20 & $41.7 \%$ & 4.5 & 0.02 & & \\
\hline & Renal & 13 & $9.6 \%$ & 2 & $4.2 \%$ & 8.06 & 0.009 & & \\
\hline & Cardiac & 21 & $15.6 \%$ & 8 & $16.7 \%$ & 5.8 & 0.01 & & \\
\hline & $\begin{array}{c}\text { Pulmonar } \\
\mathbf{y}\end{array}$ & 10 & $7.4 \%$ & 6 & $12.5 \%$ & 1.1 & 0.2 & & \\
\hline & Poisoning & 5 & $3.7 \%$ & $\mathbf{0}$ & $0 \%$ & & & & \\
\hline & Sepsis & $\mathbf{0}$ & $0.0 \%$ & 2 & $4.2 \%$ & & & & \\
\hline
\end{tabular}

Table (2) shows association between diagnosis and mortality in studied groups, there was significant statistical association between diagnosis and mortality in general and at the level of individual subgroups except for pulmonary subgroup.

There were 5 cases of poisoning, all of them survived and there were 2 cases of sepsis, both of them died. 
Table (3): Relation between (APACHE II score, CRP, albumin and thyroid functions) and mortality in whole patients:

\begin{tabular}{|c|c|c|c|c|c|c|}
\hline & \multicolumn{2}{|c|}{$\begin{array}{c}\text { Group I } \\
\text { Survivor }(n=135)\end{array}$} & \multicolumn{2}{|c|}{$\begin{array}{c}\text { Group II } \\
\text { Non-survivor }(n=48)\end{array}$} & \multirow[t]{2}{*}{ T value } & \multirow[t]{2}{*}{$P$ value } \\
\hline & Mean & SD & Mean & SD & & \\
\hline APACHE II & 13.04 & 6.06 & 20.71 & 6.56 & -7.367 & $<0.001$ \\
\hline CRP & 35.60 & 24.27 & 57.25 & 32.38 & -4.841 & $<0.001$ \\
\hline Albumin & 3.33 & 0.86 & 2.86 & .90 & 3.25 & 0.001 \\
\hline TT3 & .88 & 0.26 & .88 & 0.26 & 0.104 & 0.917 \\
\hline TT4 & 9.87 & 2.39 & 8.45 & 2.84 & 3.36 & 0.003 \\
\hline FT3 & 2.00 & 0.42 & 1.39 & 0.51 & 8.03 & $<0.001$ \\
\hline FT4 & 1.27 & 0.36 & 1.19 & 0.30 & 1.479 & 0.141 \\
\hline TSH & 1.26 & 1.25 & .88 & 0.28 & 2.115 & 0.001 \\
\hline
\end{tabular}

Table (3) shows relation between APACHE II score, CRP, albumin and thyroid functions and mortality in whole cases of studied groups, there were significant statistical differences between died and survived groups as regarding APACHE II score, CRP, Albumin, FT3, TSH and TT4 (P < 0.05), while there were non-significant statistical differences as regarding TT3 and FT4.

Table (4): Correlations between thyroid functions and other variables

\begin{tabular}{|c|c|c|c|c|c|c|}
\hline & & TT3 & TT4 & FT3 & FT4 & TSH \\
\hline & $\mathbf{r}$ & -0.018 & $-0.393^{\text {** }}$ & $-0.382^{* *}$ & $-0.218^{* *}$ & -0.194 \\
\hline \multirow[t]{3}{*}{ APACHE II score } & $P$ value & 0.811 & 0.000 & 0.000 & 0.003 & 0.008 \\
\hline & $\mathbf{N}$ & 183 & 183 & 183 & 183 & 183 \\
\hline & $\mathbf{r}$ & -0.070 & -0.113 & $-0.244^{* * *}$ & -0.099 & -0.131 \\
\hline \multirow[t]{3}{*}{ CRP } & $P$ value & 0.349 & 0.129 & 0.001 & 0.181 & 0.077 \\
\hline & $\mathbf{N}$ & 183 & 183 & 183 & 183 & 183 \\
\hline & $\mathbf{r}$ & -0.134 & $0.646^{* * *}$ & $0.269^{* *}$ & 0.139 & $0.171^{*}$ \\
\hline \multirow[t]{2}{*}{ Albumin } & $P$ value & 0.071 & 0.000 & 0.000 & 0.060 & 0.021 \\
\hline & $\mathbf{N}$ & 183 & 183 & 183 & 183 & 183 \\
\hline
\end{tabular}

*. Correlation is significant if $\leq 0.05$.

**. Correlation is significant if $\leq 0.01$.

Table (4) shows that the level of FT3 showed significant negative correlation with APACHE II score $(r=-0.382, p=0.000)$, CRP $(r=-0.244, p$ $=0.001)$ and significant positive correlation with albumin $(r=0.269, p=0.000)$. The level of TSH showed significant negative correlation with APACHE II score $(r=-0.194, p=0.008)$ and significant positive correlation with albumin $(\mathrm{r}$ $=0.171, \mathrm{p}=0.021)$. The level of TT4 showed significant negative correlation with APACHE II score $(\mathrm{r}=-0.393, \mathrm{p}=0.000)$ and significant positive correlation with albumin $(\mathrm{r}=-0.646, \mathrm{p}=$ 0.000). The level of FT4 showed significant negative correlation with APACHE II score $(r=$ $0.218, p=0.003)$. The level of TT3 showed nonsignificant correlation with APACHE II score, CRP or albumin. 
Graph (1\&2) \&Table (5): ROC curve showing performance of thyroid functions,APACHE II score, CRP and albumin to predict ICU mortality in whole patients.
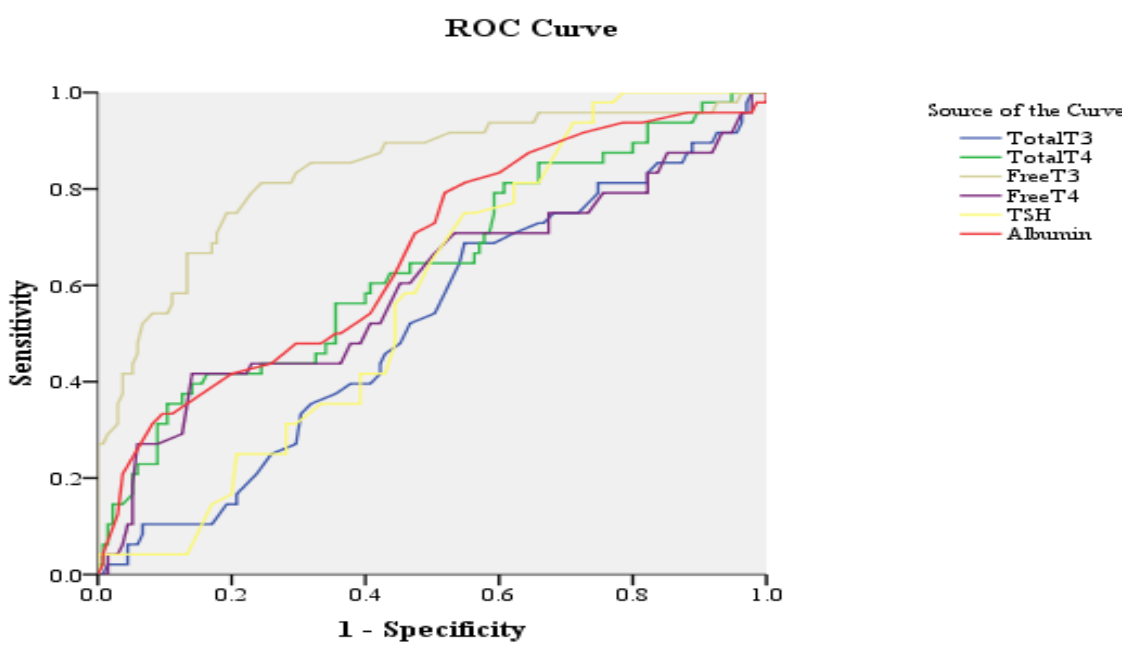

Diagonal segments are produced by ties

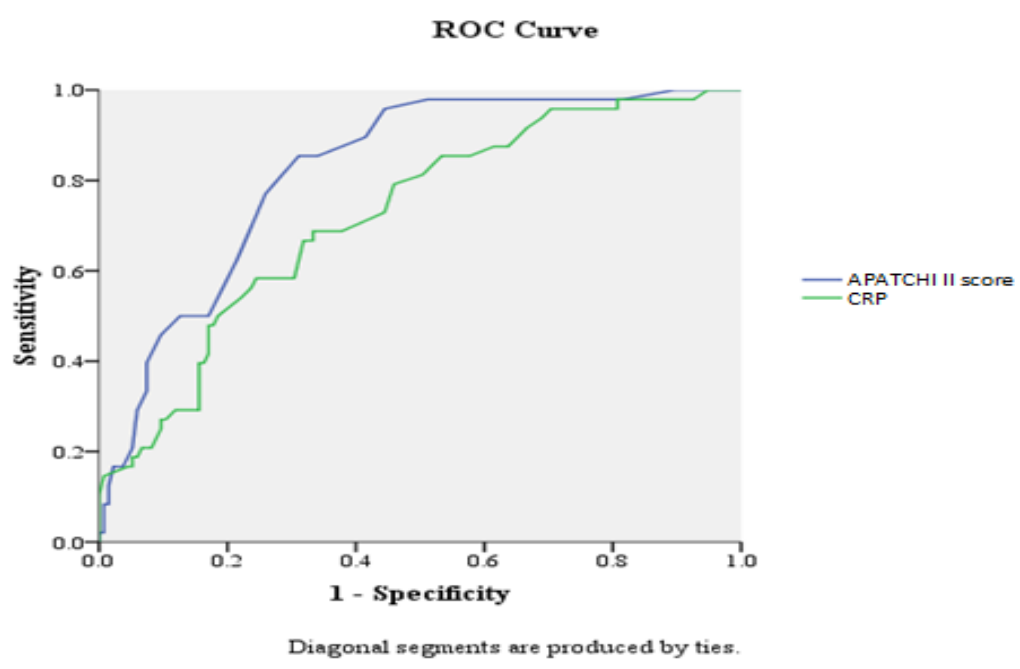

\begin{tabular}{|c|c|c|c|c|c|c|c|}
\hline \multirow{2}{*}{$\begin{array}{l}\text { Test Result } \\
\text { Variable(s) }\end{array}$} & \multirow{2}{*}{$\begin{array}{l}\text { Area } \\
\text { under } \\
\text { curve }\end{array}$} & \multirow[b]{2}{*}{$P$ value } & \multicolumn{2}{|c|}{$95 \% \mathrm{CI}$} & \multirow[b]{2}{*}{ Cutoff value } & \multirow{2}{*}{$\begin{array}{c}\text { Sensitivity } \\
(\%)\end{array}$} & \multirow{2}{*}{$\begin{array}{c}\text { Specificity } \\
(\%)\end{array}$} \\
\hline & & & $\begin{array}{l}\text { Lower } \\
\text { Bound }\end{array}$ & $\begin{array}{l}\text { Upper } \\
\text { Bound }\end{array}$ & & & \\
\hline TT3 & 0.519 & 0.695 & 0.425 & 0.613 & & & \\
\hline TT4 & 0.640 & 0.004 & 0.547 & 0.734 & $<9.08$ & 56.2 & 64.4 \\
\hline FT3 & 0.838 & $<0.001$ & 0.768 & 0.909 & $<1.845$ & 81.2 & 75.6 \\
\hline FT4 & 0.596 & 0.048 & 0.495 & 0.698 & $<1.215$ & 60.4 & 54.8 \\
\hline TSH & 0.579 & 0.106 & 0.495 & 0.662 & & & \\
\hline Albumin & 0.667 & 0.001 & 0.577 & 0.756 & $<3.35$ & 70.8 & 52.6 \\
\hline $\begin{array}{l}\text { APACHE II } \\
\text { score }\end{array}$ & 0.822 & $<0.001$ & 0.759 & 0.884 & $>15.5$ & 85.4 & 68.9 \\
\hline CRP & 0.722 & $<0.001$ & 0.641 & 0.803 & $>\mathbf{3 7}$ & 68.8 & 66.7 \\
\hline
\end{tabular}


Graph (1)\&Table (5) shows that by ROC curve analysis, the best cutoff values for predicting mortality were FT3 of 1.845 with sensitivity $81.2 \%$ and specificity $75.6 \%(\mathrm{P}<0.001)$, albumin of 3.35 with sensitivity $70.8 \%$ and specificity $52 . \%(\mathrm{P}=0.001) \quad$ FT4 of 1.215 with sensitivity $60.4 \%$ and specificity $54.8 \%(\mathrm{P}=0.048)$ and TT4 of 9.08 with sensitivity $56.2 \%$ and specificity $64.4 \%(\mathrm{P}=0.04)$. Patients with values below these cutoff values were at higher risk of mortality.

Graph (2) \&Table (5) shows that by ROC curve analysis, the best cutoff values for predicting mortality were APACHE II score of 15.5 with sensitivity $85.4 \%$ and specificity $68.9 \%$ ( $\mathrm{P}<$ 0.001 ) and CRP of 37 with sensitivity $68.8 \%$ and specificity $66.7 \%(\mathrm{P}<0.001)$. Patients with values above these cutoff values were at higher risk of mortality.

Table (6): Univariate logistic regression to detect odds ratios of variables (APACHE II score, CRP, albumin and thyroid functions) for predicting ICU mortality.

\begin{tabular}{|c|c|c|c|c|c|}
\hline & \multirow{2}{*}{ B } & \multirow{2}{*}{$P$ value } & \multirow{2}{*}{ OR } & \multicolumn{2}{|c|}{$95.0 \% \mathrm{CI}$} \\
\hline & & & & Lower & Upper \\
\hline APACHE II score & 0.180 & $<0.001$ & 1.197 & 1.122 & 1.277 \\
\hline CRP & 0.026 & $<0.001$ & 1.026 & 1.014 & 1.039 \\
\hline Albumin & -0.632 & 0.002 & 0.532 & 0.357 & 0.793 \\
\hline TT3 & -0.069 & 0.917 & 0.933 & 0.255 & 3.410 \\
\hline TT4 & -0.212 & 0.001 & 0.809 & 0.710 & .921 \\
\hline FT3 & -2.873 & $<0.001$ & 0.057 & 0.023 & 0.142 \\
\hline FT4 & -0.882 & 0.143 & 0.414 & 0.127 & 1.348 \\
\hline TSH & -1.010 & 0.019 & 0.364 & 0.157 & 0.847 \\
\hline
\end{tabular}

Table (6)shows that by univariate logistic regression, the increased APACHE II score and CRP could significantly predict the increased risk of mortality (odds ratio $>1$ ) while decrease albumin , TT4, FT3 and TSH could also significantly predict the increased risk of mortality (odds ratio <1), (all $\mathrm{P}<0.05)$. TT3 and FT4 showed a non-significant prediction for mortality. 
Table (7): Multivariate logistic regression to detect independent predictors of ICU mortality.

\begin{tabular}{|c|c|c|c|c|c|c|}
\hline \multicolumn{2}{|c|}{ Model } & -2 Log likelihood & \multicolumn{2}{|c|}{ Cox \& Snell R Square } & \multicolumn{2}{|c|}{ Nagelkerke R Square } \\
\hline \multicolumn{2}{|c|}{1} & 156.920 & \multicolumn{2}{|c|}{0.254} & \multicolumn{2}{|c|}{0.372} \\
\hline \multicolumn{2}{|c|}{2} & 138.657 & \multicolumn{2}{|c|}{0.325} & \multicolumn{2}{|c|}{0.476} \\
\hline \multicolumn{2}{|c|}{3} & 122.617 & \multicolumn{2}{|c|}{0.382} & \multicolumn{2}{|c|}{0.558} \\
\hline \multicolumn{2}{|c|}{4} & 117.665 & \multicolumn{2}{|c|}{0.398} & \multicolumn{2}{|c|}{0.583} \\
\hline \multirow{2}{*}{\multicolumn{2}{|c|}{ Model }} & \multirow{2}{*}{ B } & \multirow{2}{*}{$P$ value } & \multirow{2}{*}{ OR } & \multicolumn{2}{|c|}{$95.0 \% \mathrm{CI}$} \\
\hline & & & & & Lower & Upper \\
\hline 1 & FT3 & -2.873 & $<0.001$ & 0.057 & $\mathbf{0 . 0 2 3}$ & 0.142 \\
\hline \multirow{2}{*}{2} & APACHE II & 0.142 & $<0.001$ & 1.153 & 1.071 & 1.241 \\
\hline & FT3 & -2.255 & $<0.001$ & 0.105 & 0.041 & 0.269 \\
\hline \multirow{3}{*}{3} & APACHE II & 0.184 & $<0.001$ & 1.202 & 1.104 & 1.308 \\
\hline & FT3 & -2.371 & $<0.001$ & 0.093 & 0.034 & 0.254 \\
\hline & TSH & -1.326 & 0.034 & 0.265 & 0.078 & 0.903 \\
\hline \multirow{4}{*}{4 final } & APACHE II & 0.172 & $<0.001$ & 1.187 & 1.089 & 1.295 \\
\hline & CRP & 0.019 & 0.030 & 1.019 & 1.002 & 1.037 \\
\hline & FT3 & -2.329 & $<0.001$ & 0.097 & 0.036 & 0.267 \\
\hline & TSH & -1.377 & 0.033 & 0.252 & 0.071 & $\mathbf{0 . 8 9 7}$ \\
\hline
\end{tabular}

Table (7) shows that by forward stepwise multivariate logistic regression analysis, the independent predictors of ICU mortality in the final model were APACHE II score $(\mathrm{P}<0.001)$ , FT3 ( $\mathrm{P}<0.001)$, CRP $(\mathrm{P}=0.03)$ and TSH $(\mathrm{P}=0.033)$.The tables also show that increasedAPACHE II score and CRP could significantly predict the increased risk of mortality (odds ratio $=1.187$ and 1.019, respectively) while decreasedFT3 and TSH could also significantly predict the increased risk of mortality (odds ratio $=0.097$ and 0.252 , respectively).

\section{DISCUSSION}

Several endocrine disorders may be encountered in intensive care patients, either due to severe stress posed by the underlying disorder or as a result of drugs used. The most commonly encountered condition is ESS, common contributors being the underlying disorder, drugs administered and nutritional status ${ }^{(\mathbf{1})}$.

The APACHE II score is the most commonly used predictor of mortality in intensive care patients. This score involves 12 routine physiological measurements, age and previous health status. It ranges from 0 to 71 points and correlates with the severity of illness ${ }^{(\mathbf{1})}$.However, this score does not consider hormonalresponses to illness, particularly serum levels of cortisol and thyroid hormones, which have been shown to be highly associated with mortality in critically ill patients $^{(\mathbf{1 0})}$.

The accurate prediction of mortality among ICU patients has several potential benefits. First, accurate predictions can aid in evaluating the performance of a particular ICU. Second, they allow a more unbiased comparison of the performance of several ICUs because the predictions

canbe used to adjust for case mix. Finally, accurate predictions provide a means of "risk adjustment" that is necessaryto control for confounding variables in studiesevaluating interventions in the $\mathrm{ICU}^{\left({ }^{(10)}\right.}$.

In our study, we found that APACHE II scores were significantly higher in non-survivors than in survived patients $(20.71 \pm 6.65$ vs $13.04 \pm 6.06$; $\mathrm{P}$ $<0.001)$. This is in parallel with other studies like Chinga-Alayo et al., ${ }^{(10)}$ and Tas et al., ${ }^{(12)}$ as they have reported that higher APACHE II scores were associated with higher mortality rates. We found that the levels of CRP were significantly higher in non-survivors than in survivors $(57.25 \pm 32.38$ vs $35.6 \pm 24.27$; p-value <0.001). These results match the findings reported by Wang et al., ${ }^{(13)}$, who found that the levels of CRP were 
significantly higher in non-survivors than in survivors and that CRP was independent predictor for mortality.

While many studies have reported association between the thyroid hormone levels and the prediction of mortality in intensive care patients like Gou et al., (14) and Taset al., ${ }^{(12)}$, other studies like Anand et al., ${ }^{(15)}$ and Mayer et al., (16) have reported that measurement of thyroid hormone levels did not have any value in predicting mortality.

In this study, levels of FT3, TSH and TT4 were significantly lower in non-survivors than in survivors $(1.39 \pm 0.51$ vs $2.00 \pm 0.42,0.88 \pm 0.28 \mathrm{vs}$ $1.26 \pm 1.25$ and $8.45 \pm 2.84$ vs $9.87 \pm 2.39$ respectively; all P < 0.05). The levels of FT3 were negatively correlated $(\mathrm{P}<0.05)$ with both APACHE II score and with CRP . while levels of TSH and TT4 were negatively correlated(P < 0.05) only with APACHE II score.

The reduction of serum thyroid hormone levels is generally agreed to be a result of concomitant impairment of both central regulation caused by decrease in the levels of TRH and the decreased pulsatile frequency of TSH secretion and by peripheral hormone metabolism caused by changes in peripheral deiodination by means of induction of type 3 deiodinase. Increased levels of cytokines,glucocorticoids, as well as catecholamines, are implicated in the dysregulation of thyroid hormones that occurs in critical illness. Moreover,elevated levels of free fatty acids and bilirubin, found in different pathological conditions, have been proposed as adjunctive factors contributing to the onset of the ESS, by indirectly promoting the reduction of hormone binding protein synthesis and the inhibition of FT3 binding to its receptor ${ }^{(17)}$.

Low T3 level in our study, match the results reported by Chinga-Alayo et al., (10) who proposed several mechanisms that may explain how acute critical illness causes lower levels of $\mathrm{T} 3$, a defect in the enzyme $5^{-}$deiodinase that converts thyroxin to $\mathrm{T} 3$, a reduction in the number of thyroid receptors mediated by interleukin $1 b$ and the presence of a thyroid protein binding inhibitor.

Regarding thyrotropin, Gangemi et al., ${ }^{(17)}$ was in agreement with our study that showed that levels of TSH were significantly lower in non survivors than in survivors. This can be attributed to the feedback setting at the pitutary level with decrease the TSH response to TRH ${ }^{(17)}$. Also high concentrations of cytokines such as TNF- $\alpha$ and IL-1 which are present during critical illness may appear to be responsible for that. Cytokines appear to mediate the interaction between the immune and neuroendocrine systems. They have been shown to suppress TSH secretion via direct and indirect pathways ${ }^{(4)}$.

On the contrary, Joosten et al., ${ }^{(18)}$ have found that levels of TSH were higher in non-survivors than in survivors. This can be attributed to hormonal changes in critical illness that may result in a mild physiological hypothyroidism, thereby limiting muscle breakdown and oxygen consumption. Increased TSH concentration would be consistent with this transient hypothyroidism. However, clinical signs are likely to be masked by high concentration of catecholamines and steroids that increase in critical illness ${ }^{(\mathbf{1 1}}$ ).

ROC curves were constructed to examine the performance of APACHE II score, CRP and different thyroid function as predictors of ICU mortality then AUC for each indicator was calculated. The AUC, optimal cutoff value, sensitivity and specificity of each indicator were determined. APACHE II score had an AUC of 0.82 which is less than the original published reports (area under the ROC curve 0.82 vs. 0.85 in original reports). The reason why APACHE IIscore performed less well may be that our outcome was ICU mortality instead of hospital mortality which was used in the original studies of APACHE II. Also,the eligibility criteria for our studyproduced a patient population much different from that in the original APACHE II studies ${ }^{(\mathbf{1 0})}$. Among the thyroid functions, FT3 had the greatest power for predicting ICU mortality as suggested by the largest AUC of about 0.83 . The AUC of FT3 was nearly the same as APACHE II score (0.82) but greater than that of CRP (0.72).

We performedunivariatelogistic regression analysis to examine the association between the ICU mortality and each indicator. The increased APACHE II score and CRP could significantly predict the increased risk of mortality (odds ratio >1) while decrease FT3, TSH and TT4 could significantly predict the increased risk of mortality (odds ratio $<1$ ); all $(\mathrm{P}<0.05)$. The same results were also reported by Wang et al., ${ }^{(13)}$ who found that the increased APACHE II score and CRP could significantly predict the increased risk of mortality while decrease any of the thyroid hormones including TT3,TT4,FT3,FT4 or TSH could significantly predict the increased risk of mortality.

A forward stepwise multivariatelogisticregression analysis was conducted to determine the independent predictors of ICU mortality and showed that increase levels of APACHE II score and CRP could independently predict the 
increased risk of mortality (odds ratio $=1.187$ and 1.019 respectively) while decrease levels of FT3 and TSH could independently predict the increased risk of mortality (odds ratio $=0.097$ and 0.252 respectively). The independent predictors of ICU mortality in the final model were APACHE II score ( $\mathrm{P}<0.001)$, FT3 ( $\mathrm{P}<0.001)$, CRP (P = $0.03)$ and TSH $(\mathrm{P}=0.033)$.

In our study, the predictive ability of FT3 was independent of APACHE II score or CRP level. This was in agreement withBello et al., ${ }^{(8)}$, Tas et al., ${ }^{(12)}$ and Wang et al., ${ }^{(13)}$. Low FT3 levels have been hypothesized to promote the feedingresistant catabolic state of prolonged critical illness ${ }^{(17)}$. In contrast,some studies showed that there was no association between FT3 levels and adverse outcomes of ICU patients ${ }^{(19)}$.

Matching with our study, Chinga-Alayo et al., ${ }^{(10)}$ also reported that decrease TSH level could significantly predict the increase risk of mortality in ICU patients.Suppression of TSH secretion by high concentration of either cortisol or cytokines which are associated with a poor outcome in severe illness might explain the prognostic value of low TSH concentration. In contrast, some studies observed no association between TSH and mortality ${ }^{(19,20)}$.

Although, in our study, levels of TT4 were lower in non-survivors than in survivors, they showed a non-significant prediction of outcome and mortality of ICU patients. This is in line with that reportedbyKumar et al., ${ }^{(20)}$.

Also, regarding TT3 and FT4 levels, in our study, they showed a non-significant prediction of mortality in ICU patients. The same results were also reported by Mayer et al., (16).

\section{CONCLUSION}

Among thyroid functions, the serum levels of both FT3 and TSH are the most powerful and independent predictors of ICU mortality. Moreover, the addition of FT3 and TSH to APACHE II score could significantly improve the ability to predict ICU outcome.

\section{REFERENCES}

1. Abdel Naby EA, Selim S, Mohsen M et al. Thyroid function in mechanically ventilated patients with acute respiratory failure: Prognostic value and its relation to high-sensitivity C-reactive protein, Egyptian Journal of Chest Diseases and Tuberculosis,2014; doi:10.1016/j.ejcdt.2014.07.020.

2. McIver B and Gorman CA. Euthyroid sick syndrome: an overview. Thyroid,1997; 7:125-132.

3. De Groot LJ . Dangerous dogmas in medicine: the nonthyroidal illness syndrome. J ClinEndocrinolMetab, 1999; 84:151-164.

4. AngelousiAG, Karageorgopoulos DE, Kapaskelis AM et al. Association between thyroid function tests at baseline and the outcome of patients with sepsis or septic shock: a systematic review. Eur J Endocrinol,2011; 164:147-155.

5. Ilias I, Stamoulis K, Rmaganidis $\mathrm{A}$ et al. Contribution of endocrine parameters in predicting outcome of multiple trauma patients in an intensive care unit. Hormones,2007 ; 6:218-226.

6. Türe M, Memiş D, Kurt I et al. Predictive value of thyroid hormones on the first day in adult respiratory distress syndrome patients admitted to ICU: comparison with SOFA and APACHE II scores. Ann Saudi Med; 25:466-472.

7. Scoscia E, Baglioni S, Eslami A et al. Low triiodothyronine (T3) state: a predictor of outcome in respiratory failure? Results of a clinical pilot study. Eur J Endocrinol,2004 ; 151:557-560.

8. Bello G, Pennisi MA, Montini L et al. Nonthyroidal illness syndrome and prolonged mechanical ventilation in patients admitted to the ICU. Chest,2009 ; 135:1448-1454.

9. Sharshar T, Bastuji-Garin S, Polito A et al. Hormonal status in protracted critical illness and inhospital mortality. Crit Care, 2011; 15:R47.

10. Chinga-Alayo E, Villena J, Evans AT et al. Thyroid hormone levels improve the prediction of mortality among patients admitted to the intensive care unit. Intensive Care Med, 2005; 31:1356-1361.

11. Rothwell PM and Lawler PG. Prediction of outcome in intensive care patients using endocrine parameters. Crit Care Med,1995 ; 23:78-83.

12. Tas A, Tetiker T, Beyazit Y et al. Thyroid hormone levels as a predictor of mortality in intensive care patients: A comparative prospective study, Wien KlinWochenschr, 2012; 124: 154-159.

13. Wang F, Pan W, Wang $\mathrm{H}$ et al. Relationship between thyroid function and ICU mortality: a prospective observation study. Critical Care, 2012; 16:R11.

14. Gou DY, Su W, Shao YC, et al. Euthyroid sick syndrome in trauma patients with severe inflammatory response syndrome. Chin J Traumatol, 2006; 9(2):115-7.

15. Anand NK, Chandro V, Sinha RS et al. Evaluation of thyroid functions in critically ill infants. Neuroendocrinology,1994; 60(2):165-72.

16. Mayer S, Schuetz P, Wieland $M$ et al. Low triiodothyronine syndrome: a prognostic marker for outcome in sepsis? Endocr, 2011; 39:167-174

17. Gangemi EN, Garino F, Berchialla $\mathrm{P}$ et al. Low triiodothyronine serum levels as a predictor of poor prognosis in burn patients. Burns, 2007; 34:817824.

18. Joosten KF, de Kleijn ED, Westerterp $\mathrm{M}$ et al. Endocrine and metabolic responses in children with meningoccocal sepsis: striking differences between survivors and nonsurvivors. Journal of Clinical Endocrinology and Metabolism, 2000; 85:37463753. 
19. Ray DC, Macduff A, Drummond GB et al. Endocrine measurements in survivors and nonsurvivors from critical illness, Intensive Care Med, 2002; 28:1301-1308.
20. Kumar Hk, Kapoor $U$, Kalia $R$ et al. Low triiodothyronine predicts mortality in critically ill patients. Indian Journal of Endocrinology and Metabolism, 2013; 17 (2):285-288. 